\title{
Inhibition of Horseradish Peroxidase (HRP) by a Nonhydrophobic Component of Urine: A Caution for Immunoassays
}

\author{
Kenneth L. Campbel1 ${ }^{1, *}$, Matthew Lopresti ${ }^{2}$ and William Lukas ${ }^{3}$ \\ ${ }^{1}$ Department of Biology, University of Massachusetts at Boston, Boston, MA 02125-3393, USA \\ ${ }^{2}$ Spinal Injury Medicine, Boston Medical Center, Boston, MA 02118, USA \\ ${ }^{3}$ Albuquerque NM, 87106, USA
}

\begin{abstract}
Undiluted urine mixed directly with HRP suppresses generation of enzyme product to less than $80 \%$ of that seen in buffer controls. Incubating dilutions of various urine preparations with HRP immobilized on concanavalin A coated microtiter plates reveals that the source of urine or HRP, and the type of HRP substrate used have minimal effect on the degree of HRP suppression; only dilutions of urine greater than 8-fold with buffer produce HRP activities equivalent to those in buffer. Treating urine with charcoal or C18 silica only partially reverses the HRP suppression. Inhibition of HRP in competitive assays biases results to the high side and in noncompetive assays biases results to the low side. The present findings suggest analysts should avoid immunoassay protocols that allow direct contact between undiluted urine and HRP reporter conjugates and should be cautious with quantitative results previously reported from assays that used undiluted urine with HRP reporters.
\end{abstract}

Keywords: Direct Immunoassays, HRP Inhibition, Horseradish Peroxidase Inhibition, Immunoassay Interferences, Urinary Assays, Urine Interference.

\section{INTRODUCTION}

Immunoassays are among the most commonly employed tools in biomedical and diagnostic research, often used in efficient, highly automated, high-throughput protocols. Readily available enzymes with high turnover such as horseradish peroxidase, HRP, are often employed as tracers which can be readily synthesized in the laboratory $[1,2]$ or purchased commercially at moderate prices that keep assay costs low. Most macromolecule assays have taken advantage of enzyme-linked immunosorbent assay (ELISA) formats which often demonstrate broad analytical ranges and reasonable limits of detection and they have been streamlined by employing single incubation protocols in which analyte binds to capture and tracer-labeled antibodies simultaneously prior to a wash step and a detection step. Small analyte assays still typically employ a competitive enzyme immunoassay (EIA) format with a single capture antibody at limiting dilution along with a tracer-labeled form of the analyte. Competitive assays, which tend to exhibit narrower analytical ranges and good limits of detection, have traditionally used a single incubation approach in which the analyte-tracer conjugate competes directly with the analyte for binding to the capture antibody. The tubes, wells, beads, or strips holding the antibody and bound analyte and/or tracer are then washed and developed with enzyme substrate.

*Address correspondence to this author at the Department of Biology, University of Massachusetts Boston, 100 Morrissey Blvd., Boston, MA 02125-3393, USA; Tel: 617-287-6676; Fax: 617-287-6650;

E-mail: Kenneth.campbell@umb.edu
The single incubation formats for both ELISA and EIA expose all the reagents in the assay, capture antibody and tracer-antibody conjugates or tracer-analyte conjugates, to all the components of the sample matrix, not just the analyte of interest. We have known for some time that components of the sample matrix such as specific binding proteins or autoantibodies can compete with capture or tracer-antibodies for binding to the analyte thereby skewing ELISA assays toward low analyte estimates, or binding tracer-ligand conjugates in EIA assays and skewing the assays toward high analyte estimates [3]. Similarly, we have known that close molecular relatives of the analyte such as precursors or metabolites can often compete for binding with capture or tracer antibodies shifting results for ELISA assays toward low or high analyte estimates depending on the efficiency of the molecular relative acting as a bridge in the reporter complex within the assay. Matrices containing close molecular relatives of the analyte will compete with the analyte and the analyte-tracer conjugate for binding to capture antibodies in EIA assays and bias results toward high values [3].

Matrix effects on the activity of the enzymes used in ELISA and EIA have received less attention. Studies characterizing HRP have warned against the use of samples preserved with compounds such as azide, or cyanide that can alter the structure of the reactive site heme porphyrin in HRP $[2,4]$. Other investigators have noted interferences by certain redox active matrix components such as ascorbate [5], cystine [6] or cysteine [7] with the multi-stage oxidationreduction-precursor-coupling reaction typically observed as 
the endpoint of HRP action [2]. The number of such active compounds is becoming more obvious with the definition of the human metabolome [8] and related projects. Bouatra et al. [7] in a thorough analysis of the metabolome data from multiple analytical platforms report that typical urine, which is a filtrate and subset of the metabolome in serum, contains at least 3079 detectible metabolites from 230 different chemical classes, most being very hydrophilic. They also find that urine contains 5-10 times the concentration of compounds found in cerebrospinal fluid or saliva while exhibiting 2-3 time the chemical diversity of those fluids. The compositional lists reported by Bouatra et al. based on HMDB data [7], Da Silva et al. based on automated flow injection NMR [9], and Gates et al. based on gas chromatography-mass spectral (GC-MS) analysis of organic acids in human urine [10] all indicate an abundance of highly soluble, multiply oxygenated, double-bond rich compounds that are often found in concentrations above $10 \mathrm{uM} / \mathrm{mM}$ of creatinine $(\geq \sim 0.1 \mathrm{mM}$ in urine), e.g., hippuric, citric, isocitric, glycolic, pyroglutamic, and threonic acids; cysteine is found in similar abundance. Such compounds either singly or in combination could easily act as chelating or reducing agents that could modify the redox status of the heme in HRP thereby altering the kinetics of subsequent dye formation, interfering with the production of the analytical signal in ELISA or EIA using HRP tracers, and altering the estimates of the analytes actually being measured. Similarly, as the HMDB [8] lists > 3000 lipids that have been detected in urine, one or more of these may modulate HRP action [1113].

The importance of such matrix metabolome effects on an EIA became apparent in a direct assay with a testosteroneHRP reporter conjugate when a wash step was mistakenly omitted prior to adding a tetramethylbenzidine (TMB)/ sodium perborate HRP substrate mixture in phosphate-citrate buffer. The wells in the plate showed a uniformly high signal, as might be expected when they all contained the same high amount of analyte tracer conjugate, except in two wells containing minimally diluted adult male human urine. In those wells the HRP signal was totally suppressed. Because suppression could not be related to antigen-antibody interactions in this situation, there had to be an effect on HRP activity caused by undiluted urine. The problem was pursued when it was realized that this could exert: 1) a positive bias on the results of this and many other direct competitive assays for urinary analytes in our own and other laboratories, 2) a negative bias on results of direct noncompetitive assays, and, 3) indeterminant biases on results reported in published work.

\section{METHODS}

HRP binds via mannose core carbohydrate side chains to the lectin concanavalin A, Con A, $[2,14]$; Con A was used as a capture agent to immobilize HRP for testing the parameters of suppression. This avoided ambiguities that would arise if analyte antibodies were used to capture ligand conjugates of HRP. Immulon 4 HBX 96-well plates (Dynatech) were coated with $2 \mathrm{ug} / \mathrm{well}$ of Con A (Polysciences 3685) by incubating the lectin with fresh plates in $50 \mathrm{mM}$ $\mathrm{Na}_{2} \mathrm{CO}_{3} / \mathrm{NaHCO}_{3}$ buffer, $\mathrm{pH}$ 9.6, for 2-16 $\mathrm{h}$ followed by blocking with $50 \mu \mathrm{L} /$ well $1 \%$ BSA in PBS or TBS for $0.5-2$ $\mathrm{h}$ and washing 5 times with $5 \mathrm{mM}$ PBS, $0.05 \%$ Tween 20 , pH 7. Pure HRP (Sigma Chemical Company, St. Louis, MO, P-8375), pregnanediol-3 $\alpha$-glucuronide- HRP conjugate (made in-house using the same HRP preparation), or testosterone-HRP (Sigma T-0648), were added at $50 \mathrm{ng} / \mathrm{well}$ in PBS or TBS buffer with $1 \mathrm{mM}$ each $\mathrm{CaCl}_{2}, \mathrm{MgCl}_{2}$, and $\mathrm{MnCl}_{2}$ (to assure Con A activity) and incubated 2-16 h prior to washing (5 times). Human adult male urine, human adult female urine, prepubertal human male urine, adult male goat urine, and adult male rat urine were incubated at varying dilutions in PBS or TBS with the prepared plates for 2-16 h prior to washing 5-10 times and development with substrate mixtures. (All human urines were obtained from volunteers associated with the laboratory and/or consenting under IRB clearance. Animal urines were collected under IACUC approval.) Substrates were added $(100 \mathrm{uL} /$ well $)$ to initiate colorimetric product formation (TMB, 3,3',5,5'-tetramethylbenzidine, Sigma T3405, $0.1 \mathrm{mg} / \mathrm{mL}$ in $0.05 \mathrm{M}$ phosphate citrate buffer, $\mathrm{pH} 5$, with $0.03 \%$ sodium perborate, Sigma $\mathrm{P} 4922$, or with $0.003 \% \mathrm{H}_{2} \mathrm{O}_{2}$ in $0.05 \mathrm{M}$ phosphate citrate buffer, pH 5; or OPD, $\sigma$-phenylenediamine, Sigma P9187, $0.4 \mathrm{mg} / \mathrm{mL}$ in $0.05 \mathrm{M}$ phosphate citrate buffer, $\mathrm{pH} 5$, with $0.4 \mathrm{mg} / \mathrm{mL}$ urea hydrogen peroxide; or ABTS, 2,2 '-azino-di(3-ethylbenzo-thazoline-6-sulfonate, Sigma A1888, 0.4 $\mathrm{mg} / \mathrm{mL}$ in $0.05 \mathrm{M}$ phosphate citrate buffer, $\mathrm{pH} \mathrm{4}$, with $0.003 \% \mathrm{H}_{2} \mathrm{O}_{2}$ ) and allowed to react for 10-20 min. Reactions were halted prior to reading by addition of $50 \mathrm{uL}$ of $100 \mathrm{~g} / \mathrm{L}$ maleic acid (TMB, OPD) or $20 \mathrm{uL}$ of $37 \mathrm{mM} \mathrm{KCN} \mathrm{(ABTS)}$ [2]. Plates were read at substrate-specific wavelengths (TMB, $450 \mathrm{~nm}$; OPD, $492 \mathrm{~nm}$; ABTS, $415 \mathrm{~nm}$ ) with an automated reader (Molecular Dynamics, SpectroMax 190). Raw absorbances across plates were normalized by expressing them as percentages of the mean maximal absorbance observed in replicated (16/plate) buffer control wells. The geometric mean and SD of fold dilution required for the assay endpoints of the urine dilution series to exceed the average result for the buffer control mean absorbance minus the 99\% confidence interval, CI, for the buffer controls replicates in each assay were computed from the duplicated urine serial dilutions in each assay. Assays were most often repeated three times for each urine and enzyme/substrate combination. An average geometric mean and the standard error of those means, SEM, were computed across all enzyme/substrate combinations for each urine used. When assays were not replicated beyond a single assay no SD was computed.

\section{RESULTS}

It can be seen in Figs. ( $\mathbf{1}$ and $\mathbf{2}$ ) and Table $\mathbf{1}$ that HRP signals are inhibited when urine is minimally diluted. The inhibition falls rapidly with dilution. Inhibition of HRP activity was observed in all undiluted human and animal urine tested. Urine from immature and mature humans and from adult male rats and goats demonstrate suppression of HRP activity until they are diluted at least $4-8$ fold in buffer prior to introduction into the assay. Urine samples diluted > 50-fold before incubation with HRP uniformly generated signals that agreed with buffer controls. However, virtually all urine samples suppressed HRP signals $>20-25 \%$ below control values when diluted $<2$ - 4-fold. 


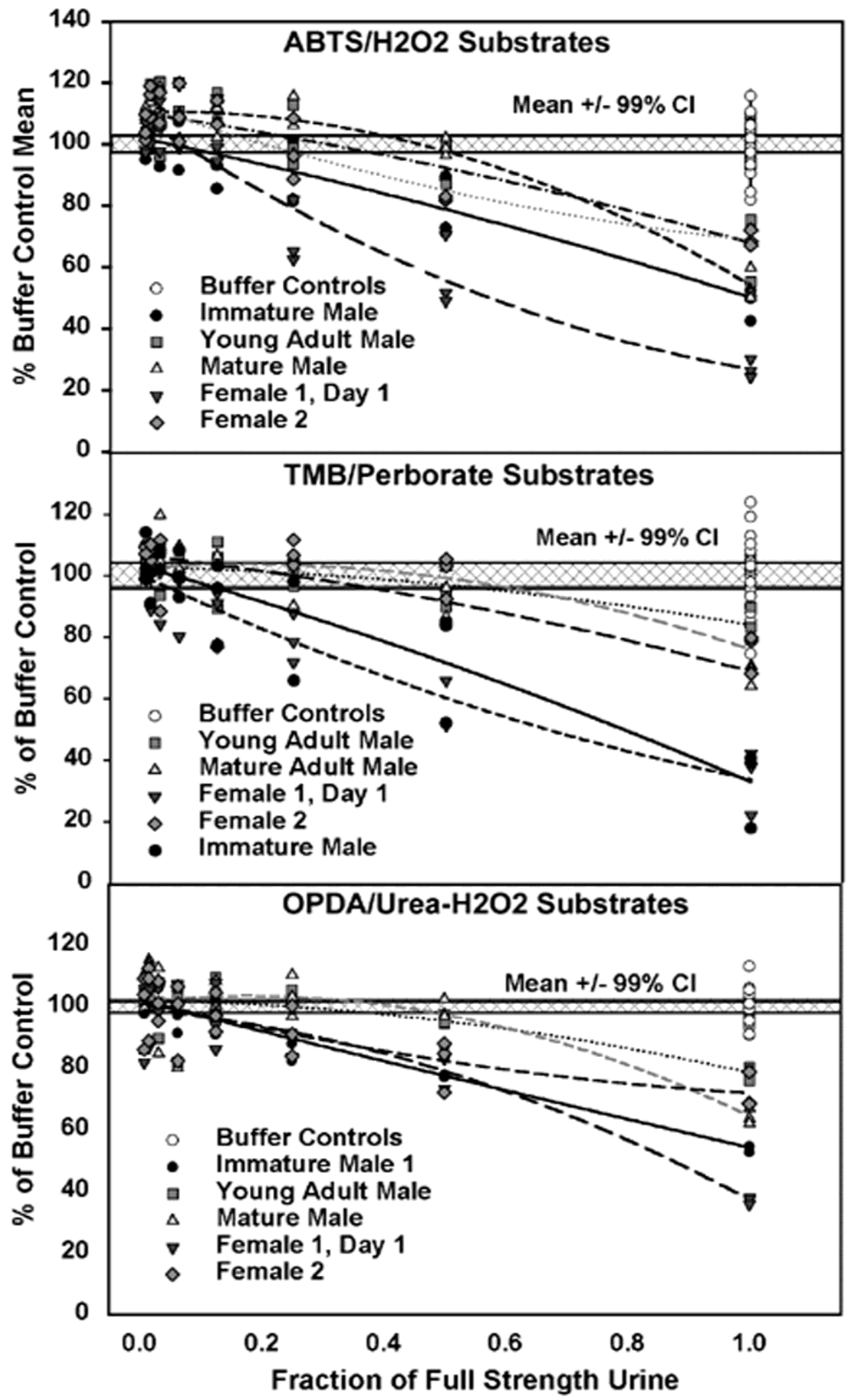

Fig. (1). Suppression of HRP signal is independent of substrate system used, variable among subjects and sampling days, and highly dependent on urine dilution. All assay results are shown and are expressed as percentages of the mean buffer control value. The range of the mean $+/-$ the $99 \%$ confidence interval is shown. The fraction of full strength urine to which the immobilized HRP was exposed ranges from 1.0 (undiluted urine) to $<0.01$ ( $>100$-fold diluted urine). Development of the HRP signal after washing out the urine samples with buffer was done using one of three substrate systems: $\mathrm{ABTS}_{\mathrm{B}}$ plus $\mathrm{H}_{2} \mathrm{O}_{2}$, TMB plus sodium perborate, or OPD plus urea- $\mathrm{H}_{2} \mathrm{O}_{2}$. 


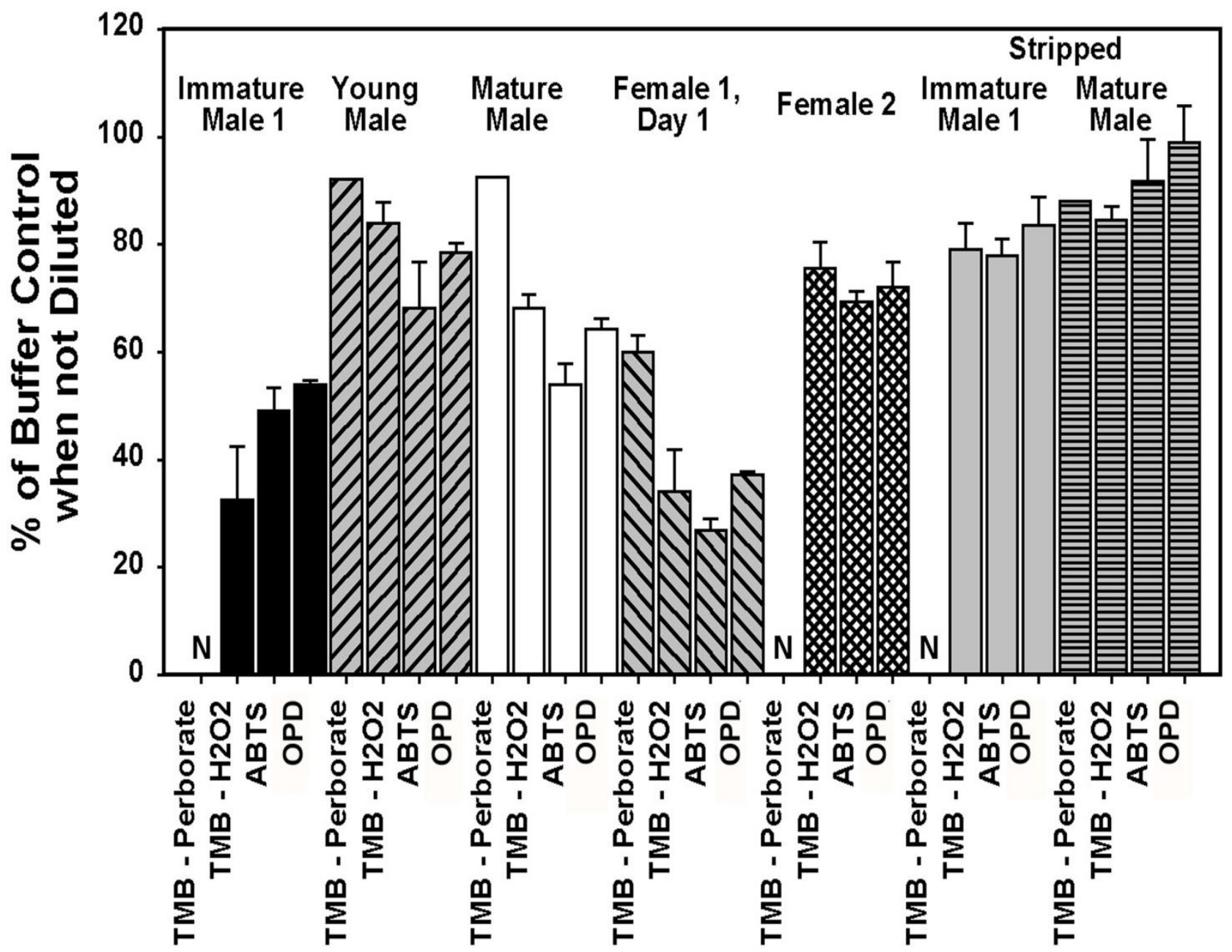

Fig. (2). Maximal signal suppression of HRP signal as a percentage of buffer control varies among samples, is consistent across substrate systems used, and is only partially eliminated by stripping urine with charcoal or C18 silica gel. Note the HRP signal in the presence of undiluted urine rises from $40-50 \%$ for the immature male urine to $75-85 \%$ for the undiluted stripped immature male urine and the signals for mature male urine sample also rise from $55-85 \%$ to $85-100 \%$ when the urine is stripped.

As seen in Fig. (2) and Table 1, there was no uniformity across samples with respect to level of HRP signal suppression. No clear pattern of suppression by a single source of samples was apparent. Suppression was seen with all types of urine tested. Fresh or frozen samples exhibited similar profiles but some of the most intense suppression was found in fresh immature male samples and frozen adult female samples. Female samples from the same individual on different days showed different profiles as did samples from different females or males.

A number of tests were run to see if the interference was peculiar to a particular substrate system. Increasing the concentration of the buffer used to dilute urines in order to prevent $\mathrm{pH}$ effects failed to eliminate suppression of HRP signals by minimally diluted urine samples (data not shown). Nor did buffers containing 4M urea mimic urinary effects (data not shown). Suppression was observed using TMB with sodium perborate or with direct addition of $0.003 \%$ $\mathrm{H}_{2} \mathrm{O}_{2}$. It was also observed using ABTS and peroxide or $\mathrm{OPD}$ and urea/peroxide. In all cases similar levels of suppression were observed (Table 1).
Several forms of HRP were tested to evaluate any dependence of the suppression on the type of HRP preparation. Similar degrees of suppression were seen regardless of the source of HRP activity. When titrated to allow a maximum of 1.5 - 2.0 optical density production from a TMB/perborate substrate within 5-10 min, all HRP preparations demonstrated similar inhibition responses (Table 1). Pure HRP, a testosterone-HRP conjugate, or a preganediol-3 $\alpha$-glucuronide-HRP conjugate or all showed the same qualitative and quantitative responses to the presence of urine at varying dilutions.

To begin characterizing the chemical nature of the interfering substance(s) several samples of immature and mature male urine were treated with $1 \mathrm{~g}$ activated charcoal/10 mL urine and/or were passed over a BakerBond 500 mg C18 silica column (J.T. Baker, Inc., 7334-06). Such treatments decreased the HRP inhibition seen with untreated urine by about $50 \%$. But it did not eliminate suppression. Thus, the inhibitory component is either hydrophilic or is only weakly hydrophobic. The lack of a $\mathrm{pH}$ effect suggests that whatever the inhibitor's identity, it is insensitive to proton concentration. 
Table 1. Fold dilution required for endpoint to exceed buffer control Mean $-99 \% \mathrm{CI}$.

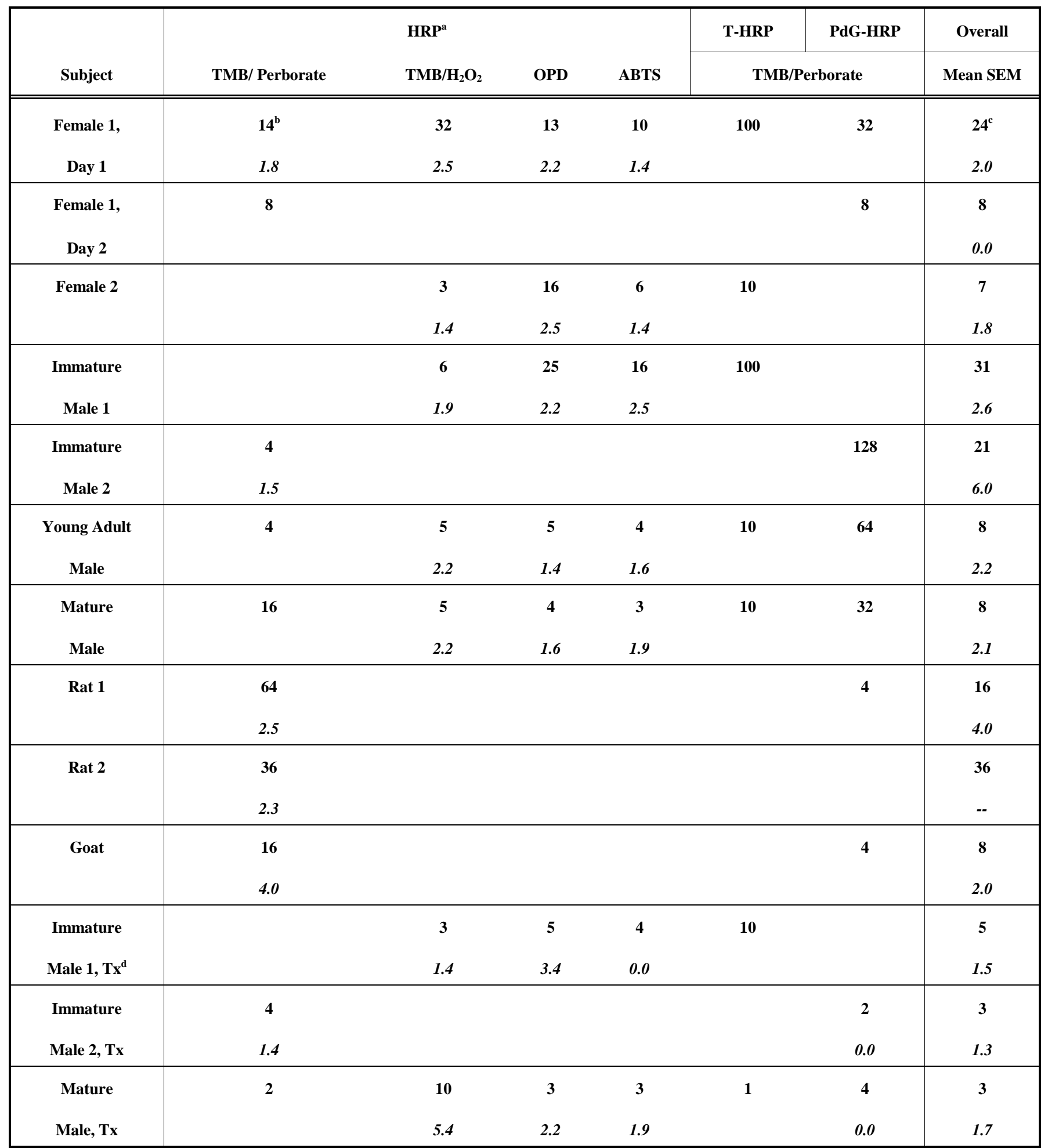

${ }^{a}$ Abbreviations: HRP, horseradish peroxidase; Perborate, sodium perborate; T-HRP, testosterone HRP conjugate; PdG-HRP, pregnanediol-3 $\alpha$-glucuronide HRP conjugate; TMB, 3,3',5,5'-tetramethyl-benzidine; OPD, $\sigma$-phenylenediamine; ABTS, 2,2'-azino-di-(3-ethylbenzothazoline-6-sulfonate).

${ }^{\mathbf{b}}$ Geometric mean and SD of fold dilution required for the assay endpoints of the urine dilution series to exceed the average result for the buffer control mean absorbance minus the $99 \%$ CI for the 16 buffer controls replicates in each assay; urine dilutions were duplicated in each assay and assays were run in triplicate if a SD is noted.

${ }^{\mathbf{c}}$ Mean and SEM: the geometric mean and standard deviation of all test means for each subject urine.

dx, stripped with charcoal. 


\section{DISCUSSION}

The compounds involved in the observed inhibition are not merely causing a spectrophotometric interference because they actually diminish the amounts of substrate converted by HRP even after the urine samples have been washed from the plates. Thus, they do not resemble the behavior of ascorbate [5] which re-reduces oxidized substrate when present during the enzyme reaction, or of digoxin [15] which binds to the enzyme-substrate complex. Moreover, they suppress the enzyme activities measured to a similar extent even when substrates generate products of very different colors. They may involve endogenously generated cyano, azide, or other amine compounds capable of interacting with the active site of peroxidase [2, 4], hydroxamic acids, hydrazides, and amides that alter spectral behavior of peroxidase as well as its kinetic characteristics [16], or homogentisic acid which inhibits catalysis at high concentrations [17]. They might also be thio-compounds such as sulfide [18], thioureas [19] or thiouracils [11] that seem to inhibit via interference with a thio group in the vicinity of the prosthetic group of the enzyme; L-cystine or cysteine reach uM concentrations in normal urine $[6,7]$ and can also inhibit HRP [20], possibly through a similar mechanism. The water soluble cations $\mathrm{Cd}^{+2}, \mathrm{Co}^{+2}, \mathrm{Cu}^{+2}, \mathrm{Fe}^{+3}$, $\mathrm{Mn}^{+2}, \mathrm{Ni}^{+2}, \mathrm{~Pb}^{+2}$ are all present in at least trace quantities in urine and are known inhibitors of HRP through either catalytic interference or enzyme conformational change [20]. If the $1 \mathrm{mM}$ of $\mathrm{Mn}^{+2}$ present in our assays during capture of HRP did inhibit HRP action, we were still able to clearly observe the effects of urine dilution and urine source. Finally, the inhibitory activity may involve some of the phenolic or aromatic compounds that are known to be able to bind to the enzyme in a hydrophobic area near the active site and to alter reaction kinetics [11-13].

Determination of the exact identity of the inhibitory species detected in this study will require HPLC fractionation in combination with MS or NMR analyses. However, knowing the identity of any inhibitors will not simplify or correct the urine-based direct analyte assays of interest in most diagnostic contexts. This is particularly so if the inhibition or HRP is a cumulative action of multiple components of the many commonly found in urine.

\section{CONCLUSIONS}

From this brief investigation we conclude: 1) it is apparent that urine in undiluted form is highly unsuited to direct immunoassay protocols that expose the HRP reporter conjugates to that urine; 2) this is true without respect to urine source, assay type, or substrate system employed; and, 3 ) the inhibition is caused by a component that is only partially removed by charcoal treatment and is probably a water soluble organic compound.

We recommend that: 1) since the inhibition diminishes rapidly with dilution of urine in buffer, it should be negligible if assays are run with urine diluted at least 10 fold in buffer before assay; 2) assays that use two-step protocols or analyte extraction that prevent direct interaction of urinary matrix components with HRP tracers should be used whenever possible because they should not be subject to this type of interference; and, 3) considerable caution should be observed in attempting to use or interpret data from previously published reports that used direct assays on undiluted urine as they would be biased to high results in competitive assays and to low results in noncompetitive assays.

The existence of urine interference with assays employing HRP generated signals has not been welldocumented and has focused on the implications of abnormal concentrations of urine constituents, e.g., homogentisic acid in alcaptanuria [17], or ascorbic acid [5] in mega-dosage with vitamin $\mathrm{C}$. The literature has not explored variations in the presence of HRP interference among normal individuals or across time for single individuals. While two-step protocols for protein assays such as hCG and LH allow urinary interferences to be largely avoided by separating the ligand capture step and the detection step involving the sensitive HRP enzyme, analysis of small ligands by competitive assay, does not afford this luxury. Dilution or prior ligand extraction/purification must be employed for such analytes.

\section{CONFLICTS OF INTEREST}

No conflicts of interest exist for any of the authors regarding publication of this work. The study design, data collection, data analysis, data interpretation, preparation of the manuscript, or decision where and when to submit the report were not influenced by any entity or funding source.

\section{ACKNOWLEDGEMENTS}

All work conducted in this study was supported by the Department of Biology, University of Massachusetts at Boston. The authors are grateful for this underwriting.

\section{REFERENCES}

[1] Campbell, K.L. Solid state assays: reagents and film technology for dip stick assays. In Non Radiometric Assays: Technology and Application in Polypeptide and Steroid Hormone Detection. Albertson, B.; Haseltine, F. Eds, Alan R Liss: New York, 1988, pp. 237-287.

[2] Tijssen, P. Practice and Theory of Enzyme Immunoassays; Elsevier Science Publishers: Amsterdam, 1985.

[3] Ezan, E.; Grassi, J. Chapter 7. Optimization. In Immunoassays. Gosling, J.P. Ed, OUP: Oxford, UK, 2000, pp. 187-210.

[4] Chen, Y.-R.; Deterding, L.J.; Tomer, K.B.; Mason, R.P. Nature of the inhibition of horseradish peroxidase and mitochondrial cytochrome c oxidase by cyanyl radical. Biochemistry, 2000, 39, 4415-4422.

[5] White-Stevens, R.H. Interference by ascorbic acid in test systems involving peroxidase. I. Reversible indicators and the effects of copper, iron, and mercury. Clin. Chem., 1982, 28, 578-588.

[6] Tompsett, S.; Fitzpatrick, J. The concentration of tryptophan, cystine, tyrosine, phenylalanine, histidine and methionine in normal human urine-microbiological assay. Br. J. Exp. Pathol., 1950, 31, 70-72.

[7] Bjorndahl, T.C.; Krishnamurthy, R.; Saleem, F.; Liu, P.; Dame, Z.T.; Poelzer, J.; Huynh, J.; Yallou, F.S.; Psychogios, N.; Dong, E.; Bogumil, R.; Roehring, C.; Wishart, D.S. The human urine metabolome. PLOS ONE, 2013, 8, e73076.

[8] Wishart, D.S.; Knox, C.; Guo, A.C.; Eisner, R.; Young, N.; Gautam, B.; Hau, D.D.; Psychogios, N.; Dong, E.; Bouatra, S.; Mandal, R.; Sinelnikov, I.; Xia, J.; Jia, L.; Cruz, J.A.; Lim, E.; Sobsey, C.A.; Shrivastava, S.; Huang, P.; Liu, P.; Fang, L.; Peng, J.; Fradette, R.; Cheng, D.; Tzur, D.; Clements, M.; Lewis, A.; De Souza, A.; Zuniga, A.; Dawe, M.; Xiong, Y.; Clive, D.; Greiner, R.; Nazyrova, A.; Shaykhutdinov, R,L.; Liang Vogel, H.J.; and 
Forsythe I. HMDB: a knowledgebase for the human metabolome. Nucleic Acids Res, 2009, 37, D603-D610. http://www.hmdb.ca.

[9] Da Silva, L.; Godejohann, M.; François-Pierre, J.; Martin, C.S.; Bürkle, A.; Moreno-Villanueva, M.; Bernhardt, J.; Toussaint, O.; Grubeck-Loebenstein, B.; Gonos, S.E.; Sikora, E.; Grune, T.; Breusing, N.; Franceschi, C.; Hervonen, A.; Spraul, M.; Moco, S.; High-resolution quantitative metabolome analysis of urine by automated flow injection NMR. Anal. Chem., 2013, 85, 5801-5809.

[10] Gates, S.C.; Sweeley, C.C.; Krivit, W.; DeWitt, D., Blaisdell, B.E. Automated metabolic profiling of organic acids in human urine. II. Analysis of urine samples from "healthy" adults, sick children, and children with neuroblastoma. Clin. Chem. 1978, 24, 1680-1689.

[11] Zaton, A.M.L.; de Aspuru, E.O. Horseradish peroxidase inhibition by thiouracils, FEBS Lett.; 1995, 374, 192-194.

[12] Dias, N.; Garcia Sanchez, F.; Gonzalez Garcia, J.A. Phenol derivatives as enhancers and inhibitors of luminol- $\mathrm{H}_{2} \mathrm{O}_{2}$-horseradish peroxidase chemiluminescence. J. Biolumin. Chemilumin., 1998, $13,75-84$.

[13] Paul, K.G.; Ohlsson, P.I. Equilibria between horseradish peroxidase and aromatic donors. Acta Chem. Scand. B, 1978, 32, 395-404.
[14] Mega, T.; Oku, H.; Hase, S. Characterization of carbohydratebinding specificity of Concanavalin A by competitive binding of pyridylamino sugar chains. J. Biochem.; 1992, 111, 396-400.

[15] Rogozhin, V.V.; Verkhoturov, V.V. Effect of antioxidants (digoxin, quercetin, and ascorbic acid) on catalytic properties of horseradish peroxidase. Biochemistry (Moscow), 1988, 63, 657661.

[16] Schonbaum, G.R. New complexes of peroxidases with hydroxamic acids, hydrazides, and amides. J. Biol. Chem., 1973, 248, 502-511.

[17] Moriwaki, Y.; Yamamoto, T.; Nasako, Y.; Ohata, H.; Takahashi, S.; Tsutsumi, Z.; Yamakita, J.; Higashino, K. 'Pseudohypouricosuria' in alcaptonuria: homogentisic acid interference in the measurement of urinary uric acid with the uricase-peroxidase reaction. Ann. Clin. Biochem., 1999, 36, 501-503.

[18] Ghadiri, M.; Kariminia, H.-R.; Azad, R. Spectrophotometric determination of sulfide based on peroxidase inhibition by detection of purpurogallin formation. Ecotoxicol. Environ. Saf, 2013, 91, 117-121.

[19] Ugarova, N.N.; Popova, I.M.; Dolmanova, I.F.; Shekhovtsova, T.N. Inhibition and inactivation of horseradish peroxidase by thiourea. Biokhimiia, 1981, 46, 1026-1034.

[20] Zollner, H. Handbook of Enzyme Inhibitors, 2nd ed., Part A; VCH: Weinheim, Germany, 1993, pp. 367-368.

Received: October 25, 2013

Revised: February 13, 2014

Accepted: February 13, 2014

(C) Campbell et al.; Licensee Bentham Open.

This is an open access article licensed under the terms of the Creative Commons Attribution Non-Commercial License (http://creativecommons.org/licenses/ by-nc/3.0/) which permits unrestricted, non-commercial use, distribution and reproduction in any medium, provided the work is properly cited. 